\title{
The effect of adipose tissue-derived stem cells in a middle cerebral artery occlusion stroke model depends on their engraftment rate
}

\author{
Saskia Grudzenski ${ }^{*}$ (D), Sebastian Baier ${ }^{2}$, Anne Ebert $^{1}$, Pim Pullens ${ }^{3}$, Andreas Lemke $^{2}$, Karen Bieback ${ }^{4}$,
} Rick M. Dijkhuizen ${ }^{5}$, Lothar R. Schad ${ }^{2}$, Angelika Alonso ${ }^{1}$, Michael G. Hennerici ${ }^{1}$ and Marc Fatar ${ }^{1}$

\begin{abstract}
Background: In the field of experimental stem cell therapy, intra-arterial (IA) delivery yields the best results concerning, for example, migrated cell number at the targeted site. However, IA application also appears to be associated with increased mortality rates and infarction. Since many rodent studies systemically apply $1 \times 10^{6}$ cells, this could also be a consequence of engrafted cell number. The aim of this study was therefore to investigate the effect of different doses of adipose tissue-derived stem cells (ASCs) on engraftment rates and stroke outcome measured in vivo using 9.4-T high-field magnetic resonance imaging (MRI).
\end{abstract}

Methods: Male Wistar rats $(n=43)$ underwent a middle cerebral artery occlusion (MCAo) for 45 or 90 min, followed by IA delivery of either saline or $1 \times 10^{6}, 3 \times 10^{5}$, or $5 \times 10^{4}$ ASCs pre-labelled with very small superparamagnetic iron oxide particles (VSOPs). MRI (9.4-T) analysis was performed $48 \mathrm{~h}$ and 9 days post-MCAo. Lesion volumes were assessed by analysis of T2-weighted images and cell signal tracking showing cell engraftment and active cell migration by an improved T2*-analysis.

Results: The ASC-derived signal intensity increased in the affected hemisphere $48 \mathrm{~h}$ post MCAo with injected cell number $(p<0.05)$. The analysis of stroke volumes revealed an increased infarction after injection of $1 \times 10^{6}$ ASCs compared to controls or application of $5 \times 10^{4} \mathrm{ASCs}(p<0.05)$. At 9 days post-MCAo, injection of $3 \times 10^{5} \mathrm{ASCs}$ resulted in reduced infarct volumes $(p<0.05)$. Correspondingly, MRI analysis revealed no changes in cell numbers between both MRI examinations but showed active ASC migration to the site of infarction.

Conclusion: Our results confirm that IA injection is an efficient way of targeting damaged brain tissue but its usefulness strongly depends on the right dose of delivered stem cells since this factor has a strong influence on migration rate and infarct volume, with better results for doses below $1 \times 10^{6}$ cells. Future challenges will include the determination of therapeutic doses for best cellular engraftment and stroke outcome.

Keywords: Adipose tissue-derived stem cell, Cell tracking, Cell engraftment, Focal ischaemia, High-field MRI, MCA occlusion, Rodent model

\footnotetext{
*Correspondence: saskia.grudzenski@medma.uni-heidelberg.de

'Department of Neurology, Universitätsmedizin Mannheim, Heidelberg

University, Theodor-Kutzer-Ufer 1-3, D-68167 Mannheim, Germany

Full list of author information is available at the end of the article
} 


\section{Background}

Stem cell (SC) therapy has gained tremendous attention as the expectation in regenerative medicine seems to be obvious: to replace diseased or dying tissue areas with new healthy cells. Adipose tissue-derived stem cells (ASCs) can be extensively extracted from subcutaneous human adult adipose tissue and are increasingly being recognised for their proliferating capacity in cell culture as well as for their multipotency [1-4]. Additionally, their immune-privileged and immunomodulatory properties potentially allow for allogeneic transplantation into immunocompetent recipients and support tissue repair through immunosuppressive effects [5-10]. Furthermore, ASCs secrete numerous trophic factors which modulate inflammation, remodelling, and apoptosis, e.g., during stroke. This suggests they can be used as an alternative to largely unsuccessful drug approaches $[9,11]$. However, a lot of important questions in this promising field of non-drug therapy have still not been answered sufficiently; for example, what is the best delivery route or the right dose of cells for application. Regarding the route of application, results indicate that, in contrast to locally transplanted SCs, systemically (that is, intravenously (IV) or intra-arterially (IA)) injected cells have potent anti-inflammatory effects, promote brain remodelling, and induce functional neurological recovery [12]. However, there are also differences within systemic application routes that can dramatically affect cell engraftment. IV injection is a minimally invasive and therefore clinically highly relevant technique, but one very important point in the field of SC therapy is the question of how to bring enough active components, that is SCs, to the target tissue. With regards to engraftment rates, IV injection leads to delayed and poor engraftment due to long-distance migration, and filtering organs (predominantly the lungs) trapping a large amount of cells [13, 14]. More promising results concerning the migration, distribution, and cell number at the target site have been obtained after IA injection. However, it seems that this benefit comes at the cost of higher mortality rates and even increased infarction [14-16]. It is questionable if this observation is necessarily linked to IA administration or to the amount of SCs injected since, despite the fact that experimental details have gained more attention in recent studies, individual settings still differ significantly and have not been tested sufficiently, especially the correct amount, that is the therapeutic dose of cells. Most of the recent studies engrafting SCs in rodents systemically used $1 \times 10^{6}$ cells [14, 16-18]. It will therefore be important to question how much influence this parameter has on SC therapy, especially on mortality rate, traceability of engrafted cells, and infarct size. Until now, no study has ever investigated the relationship between different doses of IA delivered stem cells, cell engraftment, and migration behaviour, as well as the effect on stroke outcome, although this is of tremendous importance with regard to stem cell treatment in humans. In this study, we have investigated the effect of different amounts of ASCs, pre-labelled with very small superparamagnetic iron oxide particles (VSOP), on cell migration and distribution as well as the effect on infarct size in vivo in rat brain parenchyma using 9.4-T small animal magnetic resonance imaging (MRI) at two given times. Cells were injected IA into the external carotid artery after middle cerebral artery occlusion (MCAo).

\section{Methods}

\section{Cell culture and ASC labelling}

Cells were processed and characterized as described previously and cultured in $5 \% \mathrm{CO}_{2}$ at $37{ }^{\circ} \mathrm{C}$ in mesenchymal stem cell (MSC) growth medium supplemented with $10 \%$ MSC growth supplement, $2 \%$ L-glutamine, and $0.1 \%$ gentamicin sulphate/amphotericin-B (MSCGM Single Quots, Lonza, Walkersville, MD, USA) [19]. Mycoplasma contaminations were excluded by regular tests during cell culture. Subcultivation was performed at densities of $2 \times 10^{5}$ cells per $75 \mathrm{~cm}^{2}$ cell culture flask to prevent confluency. For experiments, the passage number was below ten. Before engraftment, ASCs were labelled with electrostatically stabilized VSOPs (VSOP 5 $\mathrm{nm}$ Flu vitro, Ferropharm, Teltow, Germany) as described previously. VSOPs have been proven to be better suited for in vivo cell labelling due to their monomer citrate coating resulting in diameters of only 4-9 $\mathrm{nm}$ and the easy and stable labelling of cells via endocytosis [20, 21]. To verify optimal growth behaviour, and to exclude any cytotoxic effect caused by cell labelling, growth curves were obtained by seeding $5 \times 10^{5}$ VSOP labelled and unlabelled ASCs and assessing vital and dead cells up to 14 days. The test was performed five times. Additionally, possible VSOP-mediated cytotoxicity was determined by measuring the release of lactate dehydrogenase (LDH) using the Cytotoxicity Detection Kit (Roche, Mannheim, Germany). Unlabelled ASCs served as negative controls and ASCs treated with $2 \%$ Triton $\mathrm{X}$ as positive controls. Values were calculated by subtracting the background control (cell culture medium) and mean values from three seeded wells for each point (negative control = unlabelled cells; positive control = unlabelled cells re-suspended with cytotoxic $2 \%$ Triton and cells labelled with $3 \mathrm{mM}$ VSOPs) were calculated. The test was performed four times. Results are described in Additional file 1: S-1 and shown in Additional file 2: Figure S1A and B.

\section{Animals}

This manuscript was written in accordance with the ARRIVE (Animal research: reporting in vivo experiments) 
guidelines [22]. Male Wistar rats originated from Charles River Laboratories (Sulzfeld, Germany) and were kept in the Central Facility for Medical Research (ZMF) of the University Medical Center, Mannheim, under a 12 h light cycle with food and drinking water available ad libitum. Animals were immunocompetent and did not receive immunosuppressive therapy.

\section{MCAo via filament model and cell application via the external carotid artery}

Anaesthesia was introduced with isoflurane $2.5 \%$ vaporised in $\mathrm{O}_{2}$ (med oxygen) in 43 male Wistar rats at the age of 12 weeks and with a weight of $383 \pm 76.2 \mathrm{~g}$. Anaesthesia was maintained at $1.5 \%$ during surgery (Abbott, Wiesbaden, Germany) via a face mask. Body temperature was maintained at $37{ }^{\circ} \mathrm{C}$ with an electric heating pad and feedback control via a rectal temperature probe. Arterial blood gases $\left(\mathrm{pO}_{2}, \mathrm{pCO}_{2}, \mathrm{pH}\right.$, oxygen saturation) and heart rate were controlled using the radiometer ABL80 Flex (Radiometer GmbH, Willich, Germany).

Right-sided MCAo via the external carotid artery (ECA) was performed as described previsouly using silicon rubber-coated monofilaments with a diameter of $390 \mu \mathrm{m}$ (Doccol Corporation, Sharon, MA, USA) $[23,24]$. Non-invasive cerebral blood flow (CBF) measurements to ensure vessel occlusion were performed by laser Doppler measurement of the affected right hemisphere using the moor VMS-PC V2.0 system (Moor Instruments, Millway, UK). Only animals with visible vessel occlusion and a significant drop in $\mathrm{CBF}$ were included in the study.

Due to the high mortality rates after MCAo of $90 \mathrm{~min}$ and administration of $1 \times 10^{6}$ cells, we included animals with a reduced occlusion time of 45 min for all groups. The group of animals receiving $5 \times 10^{4}$ cells all underwent MCAo for $45 \mathrm{~min}$. After MCAo, $0.5 \mathrm{ml} \mathrm{NaCl} \mathrm{0.9 \%}$ was injected containing no cells (control animals; MCAo $45 \mathrm{~min}, n=8$; MCAo $90 \mathrm{~min}, n=9), 1 \times 10^{6}$ ASCs (MCAo $45 \mathrm{~min}, n=4$; MCAo $90 \mathrm{~min}, n=3$ ), $3 \times 10^{5}$ ASCs (MCAo $45 \mathrm{~min}, n=6$; MCAo $90 \mathrm{~min}, n=6$ ), or $5 \times 10^{4}$ ASCs $(n=7$; all MCAo $45 \mathrm{~min})$. After rinsing with $0.15 \mathrm{ml} \mathrm{NaCl} 0.9 \%$, the ECA was ligated permanently and ligation on the common carotid artery was removed to allow reperfusion. The laser Doppler probe was removed and both wounds were closed. Mortality rates are described in Additional file 1: S-2.

\section{MRI measurements}

Infarct localization and cell signals were measured $48 \mathrm{~h}$ and 9 days post MCAo in vivo using a 9.4-T Biospec 94/ 20 USR small animal system equipped with $740 \mathrm{mT} / \mathrm{m}$ gradients and a $1 \mathrm{H}$ surface cryogenic probe (Bruker, Ettlingen, Germany). An ischaemic lesion was defined based on hyperintense $\mathrm{T} 2$-weighted images.
Diffusion-weighted images (DWIs) and the corresponding maps of apparent diffusion coefficient (ADC) were obtained to identify signals obtained by T2- and T2\%-weighted images as an infarct and tissue developments such as necrosis and oedema. DWIs were acquired using a respiratory-triggered single-shot spinecho echo-planar imaging (SS-EPI) sequence using the following parameters: 30 gradient directions and seven b-values $(b=0,500,1000,1500,2000,2500,3000 \mathrm{~s} /$ $\mathrm{mm}^{2}$ ) along each direction, $\Delta / \delta=10 / 2.5 \mathrm{~ms}$, TR/TE $=$ $3000 / 21.5 \mathrm{~ms}, \mathrm{FOV}=14 \times 11 \mathrm{~mm}$, matrix size $=100 \times 78$, 20 slices with a slice thickness/spacing of $0.8 / 0.2 \mathrm{~mm}$, bandwidth $=300000 \mathrm{~Hz}, \mathrm{NEX}=1$, and a total acquisition time of 9 min. ADC maps were calculated using Bruker software. T2-weighted images were acquired with a coronal T2-weighted RARE sequence using the same geometry as the SS-EPI: TR/TE $=3300 / 60 \mathrm{~ms}$, echo train length $=4, F O V=14 \times 11 \mathrm{~mm}$, matrix size $=320 \times 256$, bandwidth $=110000 \mathrm{~Hz}, \mathrm{NEX}=4$, and a total acquisition time of $4 \mathrm{~min}$.

Labelling cells with VSOPs leads to a strong decrease in the transverse relaxation time of water protons diffusing close to the cells, resulting in turn in signal loss in T2*-weighted gradient echo images [25]. Thus VSOPlabelled cells can be visualized by decreased signals in T2"-weighted gradient echo images. Visualization was realised by an axial gradient-echo FLASH sequence $(\mathrm{TR}=50 \mathrm{~ms}, \mathrm{TE}=8.7 \mathrm{~ms}, \mathrm{FA}=15, \mathrm{FOV}=26.88 \times$ $17.92 \times 8.96 \mathrm{~mm}^{3}, \mathrm{MA}=768 \times 512 \times 256, \mathrm{NA}=2, \mathrm{t}_{\mathrm{acq}}=$ $2 \mathrm{~h} 23 \mathrm{~min}$, Res $=35 \times 35 \times 35 \mu^{3}$ ).

\section{MRI analysis of infarct sizes and cell signal intensity}

All analyses were performed blind to the treatment protocol or functional outcome of the tested animals. MRI analysis was performed $48 \mathrm{~h}$ post-stroke. The difference in cell signal intensity $(\Delta \mathrm{CSI})$ was measured $48 \mathrm{~h}$ post MCAo in seven T2*-weighted MR images per animal, exactly defined by anatomical structures. The affected and contralateral hemisphere was defined as the region of interest (ROI) and mean signal intensity as well as standard deviation (SD) were measured within each ROI using Image J software (National Institute of Health, MD, USA). The mean $\triangle$ CSI between affected (affect. hemi) and contralateral hemisphere (contralat. hemi) was then calculated and averaged over seven slices using the following formula:

$$
\begin{aligned}
\Delta C S I= & \sqrt{\left(\frac{\text { SD-ROIcontralat.hemi }}{\text { mean-ROIcontralat.hemi }}\right)^{2}} \\
& +\left(\frac{\text { SD-ROIaffect.hemi }}{\text { mean-ROIaffect.hemi }}\right)^{2}
\end{aligned}
$$

For infarct analysis, twenty T2-weighted MR images per individual were obtained and analysed. The hyperintense 
infarct area of every MRI slide was calculated using Image J. The area was then multiplied by slice thickness to calculate infarct volumes per MRI slide. The infarct area of the interslice gaps was calculated as the mean infarct area of two neighbour slices. The volumes of interslice gaps were then also calculated by multiplying the intergap thickness by the mean infarct area of two neighbour slices. Final infarct volumes were obtained by adding all the volumes up and were calculated as a percentage of the total individual brain volume of each animal (which was calculated in the same way).

Residual infarct sizes 9 days post-MCAo were calculated as the percentage of infarct sizes obtained after 48 $\mathrm{h}$ to determine individual changes in infarct size in each animal. Due to signal changes within 9 days caused by tissue transformation, ambiguous hypointense signals in T2*-weighted images had to be re-analysed by deleting unspecific signals and leaving ASC-derived hypointense voxels. Therefore, all obtained T2\%-weighted images per animal (twenty MRI slices corresponding to the numbers of T2-weighted images) were corrected for inhomogeneities using bias field correction [26]. Brains were segmented using a customized version of the brain extraction tool in FSL (Oxford Centre for Functional Magnetic Resonance Imaging of the Brain (FMRIB)'s Software Library). Images were normalized by setting the individual image mean to 1000. All brains were aligned using FSL-FLIRT (FMRIB's Linear Image Registration Tool) as described previously [27]. In Matlab (The MathWorks Inc., Natick, MA, USA) the de-noised (median filter) image was subtracted from the original image, and the absolute value of the result was taken. Finally, a wiener filter (local noise reduction) was applied. Voxels in the affected hemisphere having intensities higher than the mean $+2 \mathrm{SD}$ of voxel intensity in the right hemisphere were considered speckled voxels. When overlaid on the original data, these voxels contained both hyper- and hypointense voxels. Based on a histogram analysis, only the hypointense voxels were selected and considered as ASC-derived signals.

\section{Histology}

After incubation of harvested brains under deep isoflurane anaesthesia by transcardial perfusion with $4 \%$ acid-free formaldehyde overnight, 2-mm blocks were dehydrated in ethanol and xylol (Roth, Karlsruhe, Germany) and embedded in paraffin. For tissue staining procedures, $4-\mu \mathrm{m}$ sections were dewaxed in xylene and rehydrated in alcohol and distilled water. Prussian blue (PB) staining was performed using the Accustain ${ }^{\circ}$ Iron Stain Kit according to the manufacturer's guidelines (Sigma-Aldrich, St. Louis, MO, USA). Nuclei were counterstained using nuclear fast red $0.1 \%$ (Merck, Darmstadt, Germany) for $10 \mathrm{~min}$. For 3,3'- diaminobenzidine (DAB) and fluorescent staining, antigen retrieval was performed using either citrate buffer (DAKO REAL target retrieval solution, $\mathrm{pH}$ 6.0; DAKO, Hamburg, Germany) or tris (hydroxymethyl)aminomethane/ethylenediaminetetraacetic acid (TRIS/EDTA) buffer, pH 9.0 (TRIS, Merck, Darmstadt, Germany; EDTA, SERVA electrophoresis, Heidelberg, Germany) depending on the antibody used. For displaying VSOP fluorescence after rehydration in alcohol, sections were incubated with 4',6-diamidino-2-phenylindole (DAPI; 1:500; KPL, Gaithersburg, USA) overnight at $4{ }^{\circ} \mathrm{C}$, washed thoroughly with $1 \times$ phosphate-buffered saline (PBS), $\mathrm{pH}$ 7.4, and mounted in Mowiol (Roth, Karlsruhe, Germany). Results are described and representative images of ASC identification and localisation via staining of $\mathrm{PB}$ and VSOP fluorescence are shown in Additional file 1: S-3 and Additional file 3: Figure S2.

$\mathrm{DAB}$ staining was performed according to the manufacturer's guidelines using the ImmPACT DAB Kit (Vector Laboratories, Burlingame, CA, USA). Antibody dilutions were 1:100 for anti-Ki67 (\#MAB4190) and 1:30 for anti-human mitochondria (\#MAB1273) (both monoclonal, mouse; Merck Millipore, Darmstadt, Germany). Cells were counterstained with hematoxylin (Hollborn\&Soehne, Leipzig, Germany). Results and representative images of human cell identification as well as viability testing via staining of human mitochondria and Ki67 are shown in Additional file 1: S-3 and Additional file 4: Figure S3A and B. After dehydrating steps in alcohol, PB and $D A B$ stained sections were preserved in Eukitt (O. Kindler $\mathrm{GmbH} \& \mathrm{CO}$, Freiburg, Germany).

\section{Microscopic imaging, datasets, and statistics}

A Leica DM 4500 B fluorescence microscope and Leica IM50 Image Manager Software were used (Leica, Wetzlar, Germany) for bright field and image acquisition.

The dataset supporting the conclusions of this article are included within the article (see data ranges, medians, and interquartile ranges (IQRs) in the Tables). For statistical analysis, a standard software package (SPSS for windows, "SPPS Inc.", Chicago, IL, USA) was used and the two-sided Mann-Whitney $U$ test was chosen for calculation of statistical comparisons. A $p$ value $\leq 0.05$ was considered significant.

\section{Results}

MRI analysis of ASC-derived signals $48 \mathrm{~h}$ post MCAo

Forty-eight hours after IA transplantation, ASCs were distributed discretely throughout the entire lesion area in the ipsilateral side of the brain as shown by hypointense dots in representative $\mathrm{T} 2{ }^{*}$-weighted images. The intensity of the hypointense signal increased visibly with the number of cells injected (Fig. 1a). To quantify this effect, the mean $\triangle$ CSI was calculated for each animal to 
a T2* 48h post MCAO

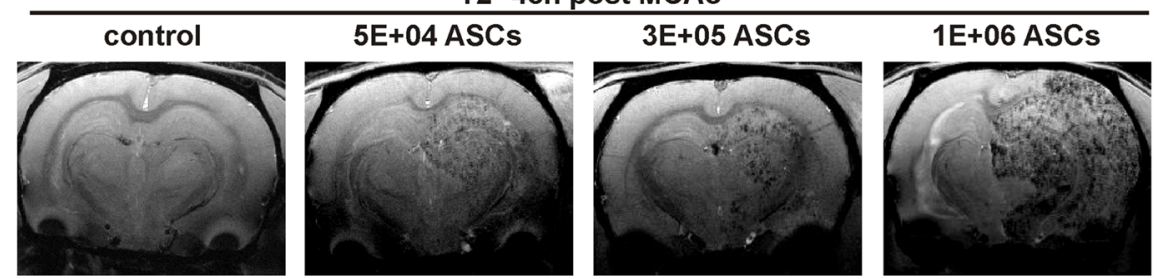

b

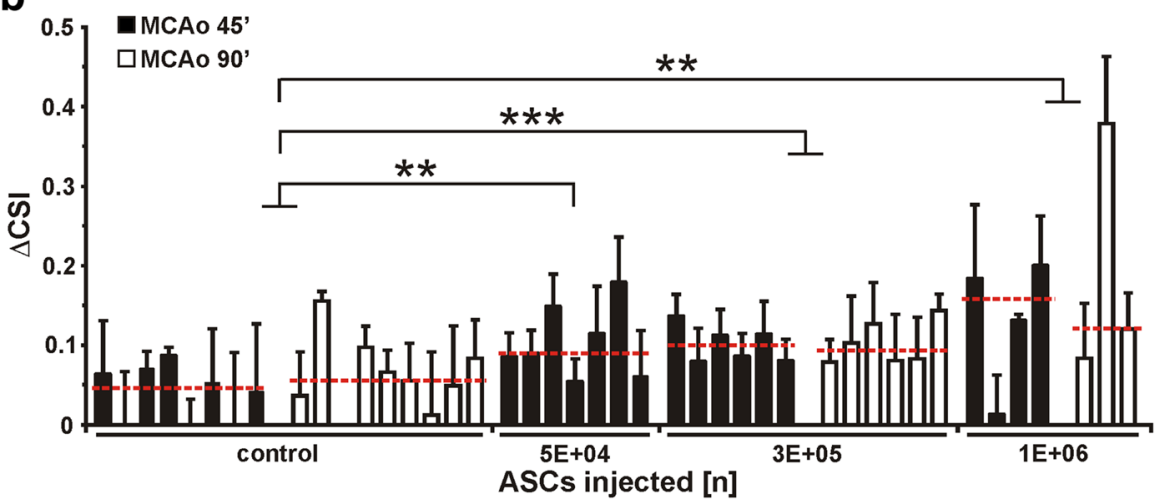

Fig. $1 \mathrm{MRI}$ analysis of ASC-derived signals $48 \mathrm{~h}$ post-MCAo. a Representative T2*-weighted images show hypointense ASC-derived signals in animals representing the control group as well as the group treated with $5 \times 10^{4}, 3 \times 10^{5}$, or $1 \times 10^{6}$ ASCs. b Differences in $\Delta$ CSI obtained $48 \mathrm{~h}$ post MCAo are shown for all treatment groups. Groups are controls ( $n=8$ for MCAo $=45$ min; $n=9$ for $M C A O=90$ min), and animals treated with $5 \times 10^{4} \mathrm{ASCs}(n=7$; all MCAo $=45 \mathrm{~min}), 3 \times 10^{5} \mathrm{ASCs}$ (both $n=6$ for MCAo $45 \mathrm{~min}$ and $\left.90 \mathrm{~min}\right)$, and $1 \times 10^{6}$ ASCs $(n=4$ for $\mathrm{MCAo}=45 \mathrm{~min} ; n=3$ for $\mathrm{MCAO}=90 \mathrm{~min}$ ). The median of each treatment group is indicated as a red dotted line. Each column represents one animal with mean $\triangle C S I$ obtained in seven brain slices per animal \pm standard deviation. ${ }^{* *} p<0.01$ for control group vs. $1 \times 10^{6}$ and $5 \times 10^{4}$ ASC group, ${ }^{* *} p<0.001$ for control group vs. $3 \times 10^{5}$ ASC group. ASC adipose tissue derived stem cell, $\triangle C S /$ difference in cell signal intensity, MCAo middle cerebral artery occlusion

evaluate differences in CSI between the ischaemic and non-ischaemic hemisphere (for data range, medians, and IQRs for $\triangle$ CSI, see Table 1). Results showed that MCAo duration did not affect $\triangle$ CSI for the control group and the group receiving $3 \times 10^{5}$ cells. For animals receiving $1 \times 10^{6}$ cells, the occlusion times could not be compared due to restricted data for the group undergoing MCAo for $90 \mathrm{~min}$; however, due to a comparable $\triangle \mathrm{CSI}$ in the first-mentioned groups, a statistical comparison was performed for every group independently of occlusion time. $\Delta$ CSI values were significantly lower for control animals than for animals treated with $5 \times 10^{4}$ cells $(p<0.01), 3 \times$ $10^{5}$ cells $(p<0.001)$, or $1 \times 10^{6}$ cells $(p<0.01)$ (Fig. $\left.1 \mathrm{~b}\right)$.

\section{MRI analysis of infarct size $48 \mathrm{~h}$ post MCAo}

To evaluate the effect of ASC engraftment on infarction, T2-weighted MR images were obtained from the same animals and MRI slices. Forty-eight hours after MCAo and ASC injection, the lesion area in the ipsilateral side of the brain was visible as a hyperintense signal and increased visibly after engraftment of $1 \times 10^{6}$ cells (Fig. 2a).

Table 1 Group sizes, data range, median, and IQR for $\triangle \mathrm{CSI}$ and infarct sizes obtained 48 h post MCAo

\begin{tabular}{|c|c|c|c|c|c|c|c|c|}
\hline \multicolumn{3}{|l|}{ Variable } & \multicolumn{3}{|l|}{$\Delta \mathrm{CSI}$} & \multicolumn{3}{|c|}{ Infarct size (\%) } \\
\hline Treatment (number of ASCs) & MCAo (min) & Group size $(n)$ & Data range & Median & IQR & Data range & Median & IQR \\
\hline \multirow[t]{2}{*}{ Control } & 45 & 8 & -0.032 to 0.087 & 0.047 & 0.078 & 0.7 to 15.8 & 6.96 & 9.25 \\
\hline & 90 & 9 & -0.143 to 0.156 & 0.055 & 0.066 & 1.1 to 17.2 & 3.23 & 6.76 \\
\hline $5 \times 10^{4}$ & 45 & 7 & 0.054 to 0.179 & 0.089 & 0.088 & 0.5 to 9.3 & 4.63 & 5.94 \\
\hline \multirow[t]{2}{*}{$3 \times 10^{5}$} & 45 & 6 & 0.079 to 0.136 & 0.099 & 0.034 & 1.7 to 10 & 5.86 & 3.83 \\
\hline & 90 & 6 & 0.079 to 0.143 & 0.093 & 0.046 & 1.1 to 13.1 & 6.82 & 6.43 \\
\hline \multirow[t]{2}{*}{$1 \times 10^{6}$} & 45 & 4 & 0.014 to 0.2 & 0.157 & 0.12 & 3.8 to 26.1 & 13.37 & 16.93 \\
\hline & 90 & 3 & 0.083 to 0.379 & 0.12 & - & 4.2 to 20.6 & 19.64 & - \\
\hline
\end{tabular}

ASC adipose tissue-derived stem cell, $\triangle C S I$ difference in cell signal intensity, IQR interquartile range, MCAo middle cerebral artery occlusion 
a T2 48h post MCAo

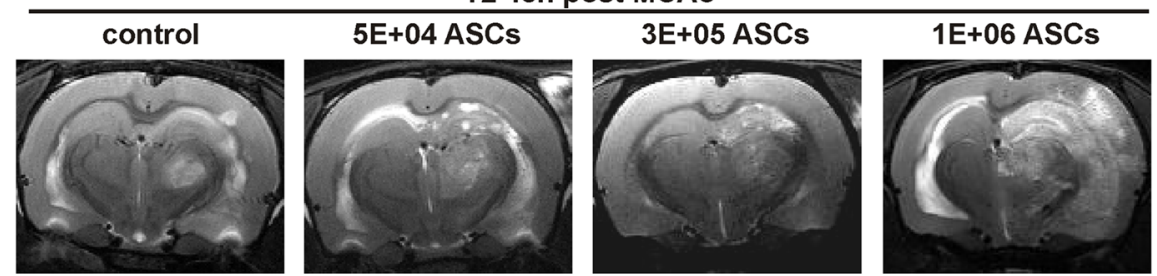

b

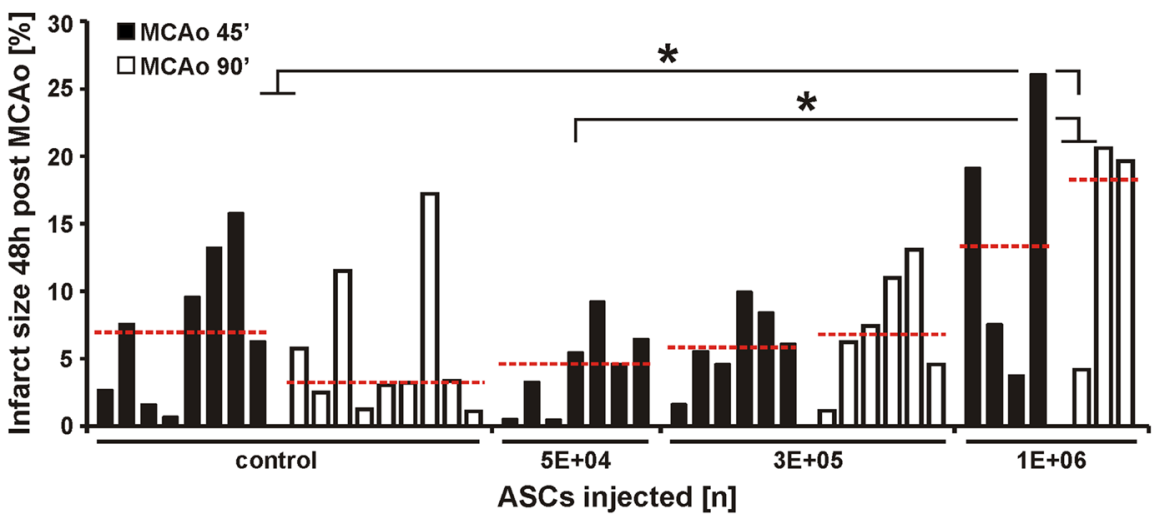

Fig. $2 \mathrm{MRl}$ analysis of infarct size $48 \mathrm{~h}$ post-MCAo. a Representative T2-weighted images displaying infarction $48 \mathrm{~h}$ post MCAo are the corresponding images to the T2*-weighted images shown in Fig. 1 and are derived from the same MRI slices and animals. $\mathbf{b}$ Differences in infarct volumes obtained $48 \mathrm{~h}$ post MCAo are shown for all treatment groups. Groups are the same as in Fig. 1. The median for each group is indicated as a red dotted line. Each column represents the infarct volume as a percentage of total individual brain volume for one animal. ${ }^{*} p<0.05$ for $1 \times 10^{6}$ ASC group vs. control group and $5 \times 10^{4}$ ASC group. ASC adipose tissue - derived stem cell, $\Delta C S /$ difference in cell signal intensity, MCAo middle cerebral artery occlusion

To evaluate the effect of ASC engraftment on infarct size, the infarct volumes were determined as a percentage of the individual total brain volume (data range, medians, and IQRs for infarct size are shown in Table 1). The results revealed no influence of occlusion time on infarct volume in the control group and the group receiving $3 \times$ $10^{5}$ cells. For animals receiving $1 \times 10^{6}$ cells, the occlusion times could not be compared due to restricted data for the group undergoing MCAo for $90 \mathrm{~min}$; however, due to comparable infarct volumes in the first-mentioned groups, a statistical comparison for every group was performed independently of occlusion time. Infarct sizes were significantly larger for animals receiving $1 \times 10^{6}$ cells compared to the control group $(p<0.05)$ or animals receiving $5 \times 10^{4}$ cells $(p<0.05)$. Infarct sizes in the group receiving $3 \times 10^{5}$ ASCs lay between those of control animals or animals injected with $5 \times 10^{4}$ cells and the group receiving $1 \times 10^{6}$ cells (Fig. $2 \mathrm{~b}$ ).

\section{T2* re-analysis and cell signal development}

To investigate the time-course of ASC-derived signal intensity, an additional MRI analysis was carried out 9 days post MCAo in the subacute to chronic stage of infarct development. The results revealed signal pattern changes within the infarcted area (Fig. 3a; dotted line, image 1) visible as hyperintense signals and most likely deriving from development of vasogenic oedema, cell lysis, and tissue cavitation, respectively, as shown by the ADC map (Fig. 3a, image 2). This resulted in ambiguous T2\%-weighted hypointense signals indicating ironlabelled ASCs or incipient tissue cavitation (Fig. 3a, image 3) which required a re-analysis, leaving specific ASC-derived hypointense voxels (Fig. 3a, image 4).

To evaluate possible changes in cell number between both MRI examinations, an assessment of $\mathrm{T} 22^{*}$-derived voxel number was performed for both time points (data range, medians, and IQRs for voxel numbers are shown in Table 2). Due to the fact that not every animal underwent both MRI examinations and voxel analysis data are restricted to smaller populations compared to Fig. 1, groups could not be compared for MCAo duration but were distinguished in the figures. Animals receiving $3 \times$ $10^{5}$ cells displayed significantly higher voxel numbers than control animals as well as animals receiving $5 \times 10^{4}$ ASCs in both MRI examinations $(p<0.01)$. Voxel numbers did not change significantly between the two MRI scans except for one animal in the $3 \times 10^{5}$ and one in the $1 \times 10^{6}$ cell group. Because of insufficient data in the $1 \times 10^{6}$ cell group, animals injected with $1 \times 10^{6}$ cells could not be analysed for statistics (Fig. 3b). 


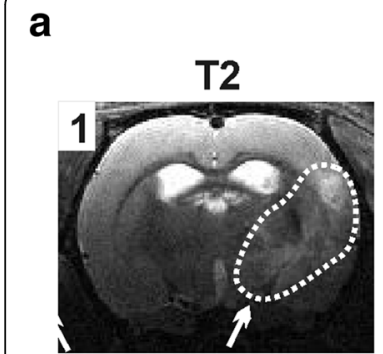

infarct area
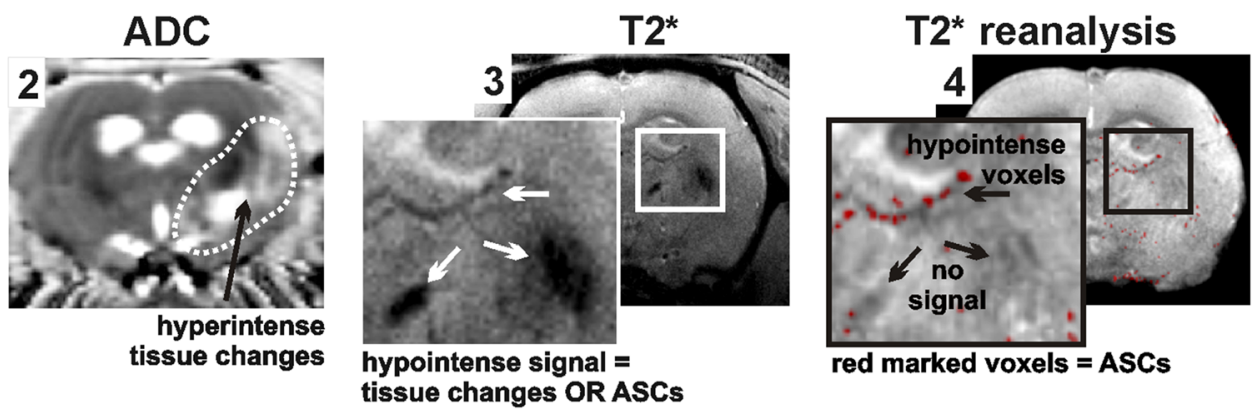

b

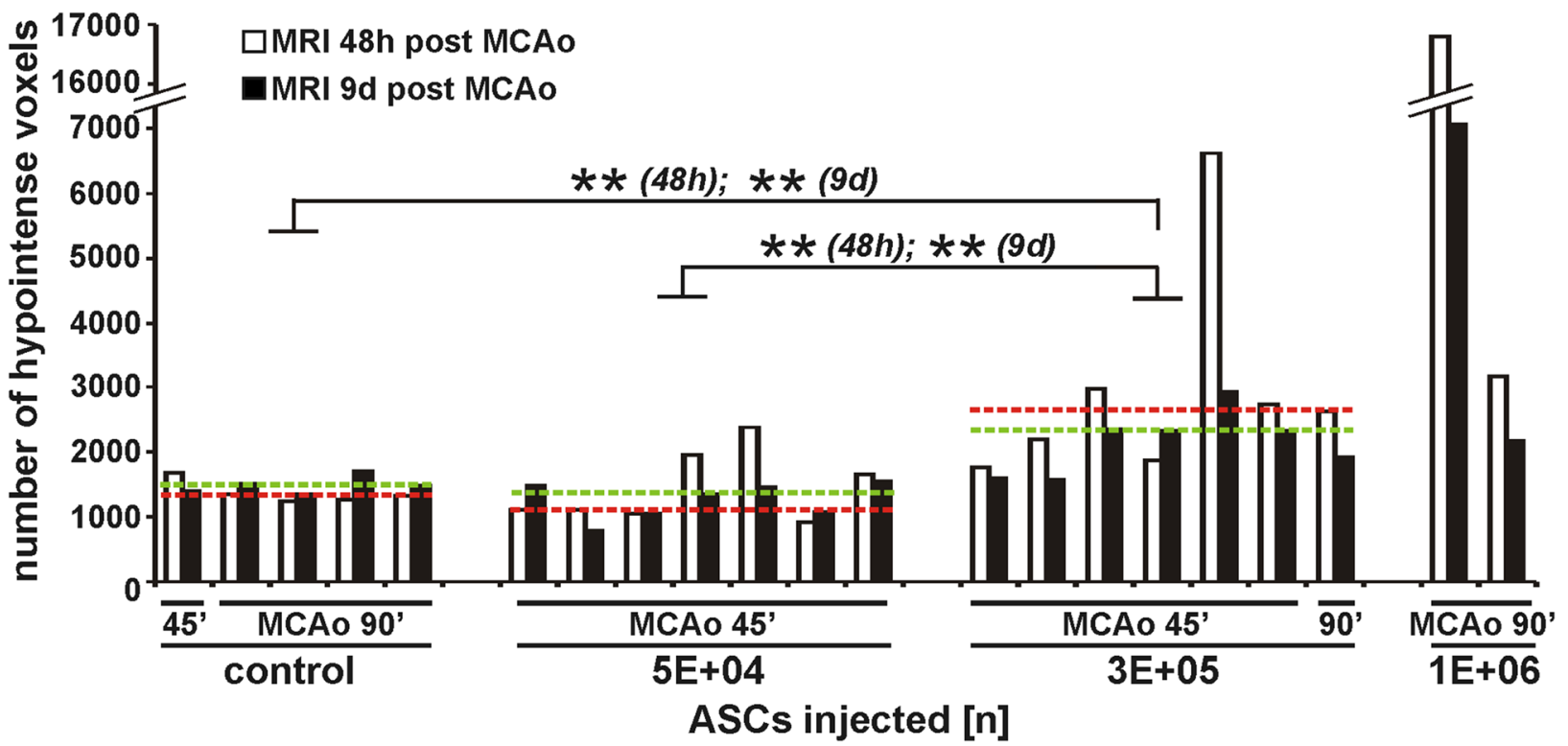

Fig. 3 T2* re-analysis and cell signal development. a Signal pattern changes within 9 days post MCAo in the infarct area (dotted line, image 1) and consequential hyperintense signals displaying tissue changes as shown by the ADC map (image 2) are presented. Resulting ambiguous T2*-weighted hypointense signals (image 3 ) were re-analysed, leaving specific ASC-derived hypointense voxels (image 4). b Differences in voxel number obtained $48 \mathrm{~h}$ and 9 days post MCAo are shown for all treatment groups. Groups were controls $(n=5 ; n=1$ for $\mathrm{MCAO}=45 \mathrm{~min} ; n=4$ for $\mathrm{MCAO}=90 \mathrm{~min})$, and animals treated with $5 \times 10^{4} \operatorname{ASCs}(n=7$; all MCAo $=45 \mathrm{~min}), 3 \times 10^{5} \mathrm{ASCs}(n=7 ; n=6$ for MCAo $=45 \mathrm{~min} ; n=1$ for $\mathrm{MCAO}$ $=90 \mathrm{~min}$ ), and $1 \times 10^{6} \mathrm{ASCs}(n=2$; all MCAo $=90 \mathrm{~min}$ ). The median for each group is indicated as a red dotted line for voxel numbers obtained 48 $\mathrm{h}$ post MCAo and as a green dotted line for voxel numbers obtained 9 days post MCAo. Each pair of columns represents values of one animal and two MRI time points. ${ }^{* *} p<0.01$ for $3 \times 10^{5}$ ASC group vs. control group and $5 \times 10^{4}$ ASC group. ADC apparent diffusion coefficient, ASC adipose tissue - derived stem cell, MCAo middle cerebral artery occlusion

Table 2 Group sizes, data range, median, and IQR for voxel numbers obtained $48 \mathrm{~h}$ and 9 days post-MCAO

\begin{tabular}{|c|c|c|c|c|c|c|c|c|}
\hline \multicolumn{3}{|l|}{ Variable } & \multicolumn{6}{|l|}{ Voxel numbers } \\
\hline & & & \multicolumn{3}{|l|}{$48 \mathrm{~h}$ post MCAo } & \multicolumn{3}{|c|}{9 days post MCAo } \\
\hline Treatment (number of ASCs) & MCAo (min) & Group size $(n)$ & Data range & Median & IQR & Data range & Median & IQR \\
\hline \multirow[t]{2}{*}{ Control } & 45 & 1 & 1250 to 1686 & 1331 & 267 & 1361 to 1706 & 1490 & 230 \\
\hline & 90 & 4 & & & & & & \\
\hline $5 \times 10^{4}$ & 45 & 7 & 931 to 2380 & 1106 & 875 & 793 to 1559 & 1369 & 433 \\
\hline \multirow[t]{2}{*}{$3 \times 10^{5}$} & 45 & 6 & 1774 to 6611 & 2636 & 1132 & 1576 to 2943 & 2330 & 744 \\
\hline & 90 & 1 & & & & & & \\
\hline $1 \times 10^{6}$ & 90 & 2 & 16795 and 3168 & - & - & 7841 and 2162 & - & - \\
\hline
\end{tabular}

ASC adipose tissue-derived stem cell, IQR interquartile range, MCAo middle cerebral artery occlusion 
Residual infarct size 9 days post MCAo and cell migration analysis

To investigate the long-term effect on infarct size, residual infarct volumes 9 days post stroke were determined as an individual percentage of the infarct size obtained $48 \mathrm{~h}$ post MCAo for each animal included in this analysis (data range, medians, and IQRs for infarct size are shown in Table 3). Due to the fact that not every animal underwent both MRI examinations the groups could not be compared for MCAo duration but were distinguished in the figures. Infarct volumes of the control group were comparable to those of the groups receiving $5 \times 10^{4}$ or $1 \times 10^{6}$ cells but differed significantly from the group receiving $3 \times 10^{5}$ cells $(p<0.05)$, which showed visibly reduced infarct sizes (Fig. 4a).

Due to improved stroke outcome in animals receiving $3 \times 10^{5}$ cells, the migration activity was assessed by comparing MRI signals visible in $\mathrm{T} 2{ }^{*}$-weighted images between both MRI examinations. Differences in hypointense signals indicated cell movement towards the ischaemic border zone as shown in one animal from the group receiving $3 \times 10^{5}$ ASCs. A strong T2*-weighted hypointense signal in the right ventricle of the ischaemic hemisphere $48 \mathrm{~h}$ post MCAo (Fig. 4b, images 1 and 2), which we also verified by voxel reanalysis, underwent signal loss as shown by MRI analysis 9 days post stroke in the same animal and MRI slide. At the same time, a hypointense spot revealed as an ASC-derived signal appeared at the ischaemic border zone in the striatum (Fig. 4b, image 3). Under histology we identified the same location and examined it for possible stem cell signals using PB staining. The staining revealed positive signals for VSOP-derived iron oxide particles (Fig. 4b, image 4).

\section{Discussion}

In this study, we investigated the influence of three different IA injected doses of ASCs on stroke outcome and stem cell homing. This was done via in vivo 9.4-T MRI in a rat model of MCAo-induced stroke.
Over the last few years, many stem cell studies focusing on stem cell administration, homing and tracking, have mainly reported on the methological details, e.g. the preparation of cell suspension of different stem cells, injection parameters, stem-cell labelling, and tracking or the time of stem-cell delivery [17, 28-33]. However, the question of the right volume of stem cells being used for transplantation was only addressed in one study injecting different numbers of human neural progenitor cells (NPCs) into the right striatum of male Wistar rats [34]. Darsalia and colleagues observed that transplantation of greater numbers of grafted NSCs did not result in a greater number of surviving cells or increased neuronal differentiation. However, since a different type of stem cell was used and the experimental settings differed, the results are only partially comparable to ours. To our knowledge, we are the first study raising the question of whether, and to what extent, the number of IA engrafted stem cells influences the parameters mentioned above and if there is an optimal number recommended for this administration.

Although the central nervous system (CNS) is an immune-privileged region, a xenogenic transplantation of human ASCs in a rat model may induce reactions of the rodent immune system. This is a problem affecting all studies testing human stem cells in rodent systems; however, even allogeneic transplantation is being discussed as including the risk of immune rejection [35]. There are conflicting reports regarding the need for immunosuppressive therapy after xenograft stem-cell therapy for cell survival and differentiation, and it is still unclear whether ASCs, despite their immunomodulatory capacities, may elicit systemic immune reactions [36]. Similar to our previous work, where we were able to observe therapeutic efficacy and stimulation of endogenous repair, we have stuck to this protocol and avoided immunosuppressive therapy, and thus possible potential effects on stroke progression and cell distribution [37]. Furthermore, our investigations where designed as a proof-of-concept study with a survival time of only 14

Table 3 Group sizes, data range, median, and IQR for residual infarct sizes obtained 9 days post MCAo

\begin{tabular}{|c|c|c|c|c|c|}
\hline \multicolumn{3}{|l|}{ Variable } & \multicolumn{3}{|c|}{ Residual infarct size (\%) } \\
\hline Treatment (number of ASCs) & MCAo (min) & Animals $(n)$ & Data range & Median & IQR \\
\hline \multirow[t]{2}{*}{ Control } & 45 & 5 & 32.16 to 74.84 & 51.1 & 25.53 \\
\hline & 90 & 4 & & & \\
\hline $5 \times 10^{4}$ & 45 & 7 & 13.52 to 60.17 & 45.02 & 37.7 \\
\hline \multirow[t]{2}{*}{$3 \times 10^{5}$} & 45 & 6 & 27.16 to 56.4 & 37.84 & 7.14 \\
\hline & 90 & 1 & & & \\
\hline \multirow[t]{2}{*}{$1 \times 10^{6}$} & 45 & 3 & 27.31 to 67.46 & 53.6 & 24.89 \\
\hline & 90 & 2 & & & \\
\hline
\end{tabular}



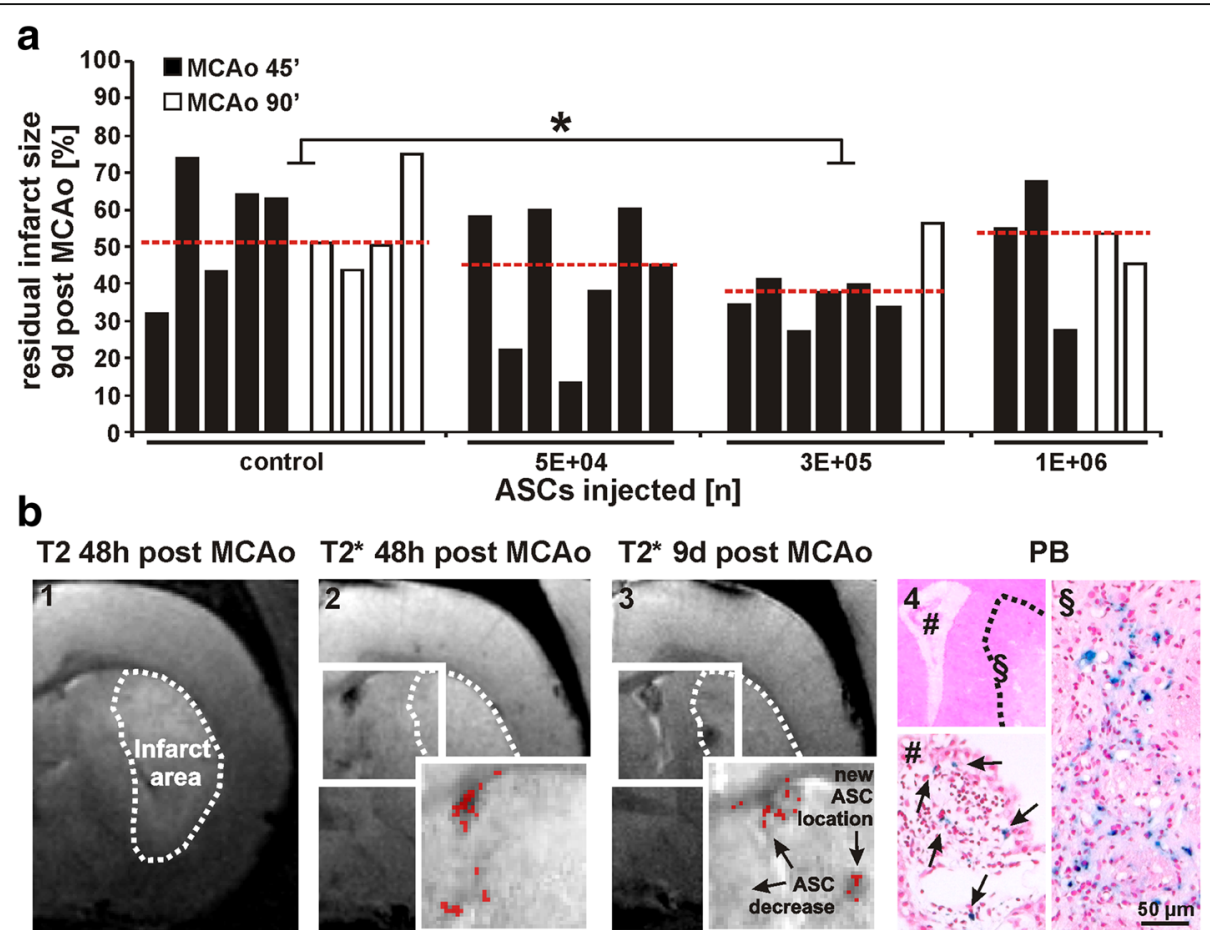

Fig. 4 Residual infarct size 9 days post MCAo and cell migration analysis. a Differences in residual infarct volumes obtained 9 days post MCAo are shown for all treatment groups. Groups are controls $\left(n=9 ; n=5\right.$ for $M C A O=45 \mathrm{~min} ; n=4$ for $M C A 0=90$ min), and animals treated with $5 \times 10^{4}$ $\operatorname{ASCs}(n=7 ;$ all MCAo $=45 \mathrm{~min}), 3 \times 10^{5} \operatorname{ASCs}(n=7 ; n=6$ for MCAo $45 \mathrm{~min} ; n=1$ for MCAo $=90 \mathrm{~min})$, and $1 \times 10^{6}$ ASCs $(n=5 ; n=3$ for MCAo $=$ $45 \mathrm{~min} ; n=2$ for $M C A O=90 \mathrm{~min}$ ). The median for each group is indicated as a red dotted line. Each column represents residual infarct size for one animal assessed as a percentage of the individual infarct size obtained $48 \mathrm{~h}$ post MCAo for each individual animal. ${ }^{*} p<0.05$ for $3 \times 10^{5}$ ASC group vs. control. b Migration activity in the ischaemic hemisphere (image 1, dotted line) of one animal treated with $3 \times 10^{5}$ ASCs is shown. A strong hypointense signal in the right ventricle of the appending T2*-weighted image (image 2) obtained after $48 \mathrm{~h}$ decreases within 9 days post MCAo with a new hypointense spot appearing in the striatum close to the infarct area (image 3). Signals are confirmed by voxel analysis. Histological analysis of the same location reveals positive PB staining (blue signals, some supported by arrows in image 4, location \# and §). ASC adipose tissue - derived stem cell, MCAo middle cerebral artery occlusion, PB Prussian blue

days, which is short compared to the 6 weeks used by, for example, Hovakimyan et al. [36].

Studies show that the injured brain is more favourable for stem cell migration than is the intact tissue. Evidence from transplantation studies indicate that the intact adult brain has a limited capacity to direct the differentiation of transplanted stem cells, whereas the developing brain and injured brain express morphogenic cues that appear to foster donor plasticity [38]. Studies transplanting NPCs either directly or IV have demonstrated that cells need a triggering signal to undergo targeted migration in the rodent CNS and that neural NPCs transplanted into the un-injured adult rodent brain undergo only limited and non-targeted migration [14, 39]. Another study using two sources of murine bone marrow stromal cells (BMSCs) demonstrated a seven-to nine-fold increase in the number of adherent BMSCs that accumulate in cerebral venules after focal transient ischaemia compared to sham-operated mice [40]. However, the aim of the study was to investigate the effect of different stem cell numbers on engraftment rate and stroke outcome after transient brain ischaemia. Therefore, we only included animals with MCAo-induced stroke.

In the past few years the question of how the biodistribution of systemically applied MSCs is regulated has also included discussion about the advantages and disadvantages of IV and IA administration. A very important question in this therapeutic field is how to bring enough stem cells to the targeted tissue. IV injection is a minimally invasive, and therefore clinically highly relevant, technique. On the other hand, it bears the disadvantage of delayed and poor engraftment due to long-distance migration and filtering organs; it was shown by several studies that up to $80 \%$ of injected cells distribute to a variety of non-targeted tissues, with most cells being trapped in the lungs, followed by the liver and spleen [41-44]. Consistently, studies comparing IV and IA administration of NPCs and BMSCs observed no, or a poor and late, engraftment in the ischaemic brain after 
IV injection [14, 16]. A second factor to bear in mind is the formation of emboli in lung vessels [42]. Cell culture-expanded MSCs are relatively large cells with an average size of $30 \mu \mathrm{m}$. Therefore, obstructive events during lung passage are expected after MSC administration which is supported by their relatively high adhesion capacity and their tendency to aggregate, leading to clogging of capillaries [42, 45, 46]. Contrary to the observation of MSC retention in the lungs, one study analysing the biodistribution of BMSCs after IA injection found a decreased deposition in the lungs and increased uptake in other organs, especially in the liver [47]. With regard to engraftment time and rates, studies comparing both application routes have demonstrated a major association between IA application and the early and increased accumulation in therapeutic target tissues $[14,16]$. However, this was associated with an impeded cerebral blood flow and higher mortality rates. In conclusion, the IA route of administration seems to be effective in avoiding pulmonary entrapment and may thus improve the biodistribution and bioavailability of transplanted MSCs in clinically relevant issues, e.g. for tissue repair.

As mentioned, IA delivery was reported to result in higher mortality rates compared to the IV application $[14,16-18]$. Since $1 \times 10^{6}$ stem cells are the standard amount for transplantation in rodents, we also included this number in our study, but we had tremendous difficulties obtaining enough data due to mortality rates being twice as high as for the other groups. Since mortality rates were only $0-33 \%$ in the other groups we cannot confirm the idea of IA delivery increasing the mortality rate per se. We hypothesize the outcome may depend on the cell amount because, in the case of IA injection, a larger cell number could be brought to the brain more quickly, bypassing systemic organs. As a consequence this may lead to increased mortality due to impeded CBF [16]. But since we have not examined other organs where cells are typically found after systemic application (e.g. lungs) we cannot exclude the possibility of pulmonary embolism resulting from cells bypassing the brain.

The comparison of infarct volumes reflected the results we obtained from mortality rates since application of $1 \times 10^{6}$ ASCs led to an increase in infarct size. This corresponds to $\mathrm{Lu}$ et al. who obtained similar results in two dogs after injection of $3 \times 10^{6}$ cells [15]. In addition to the impeded blood flow observed by Walczak et al. [16], cell injection could lead to occlusion of cerebral microvessels and thus to comprised microvascular circulation and increased infarct size. Another possibility leading to disturbed blood flow is the fact that MSCs have been shown to possess blood clotting properties by triggering the pro-coagulatory cascade via surface expression of tissue factors. This in turn may cause thromboembolism promoting mechanical vascular obstruction [48-
51]. This closes the loop to immunological complications of intravascular stem-cell applications derived by strong immunosuppressive properties that may amplify the poststroke immune deficiency syndrome and hence the risk for infections [52-55]. However, the majority of pre- and clinical data support the notion that embolic events are very rare and in the majority of cases are a mild side effect of intravenous infusion, which can be easily circumvented by adding anticoagulants such as heparin during cell infusion [56].

In our study, an occlusion time-dependent effect could not be observed possibly due to the model-adherent variability in infarct sizes we obtained. At 9 days post MCAo, the mean infarct size in the $3 \times 10^{5}$ ASC group decreased about $30 \%$ whereas infarct sizes in the other groups were comparable to the infarct size in the control group. Where animals received $1 \times 10^{6}$ ASCs this is consequential due to higher initial infarct sizes, but for the group receiving $5 \times$ $10^{4}$ ASCs one could speculate that this cell amount is not high enough to affect stroke recovery positively. A positive reduction of infarct size up to $54 \%$ could also be observed in previous studies after IA injection in Wistar and Sprague-Dawley rats, but since $1 \times 10^{6}$ cells or more were used this is contrary to what we found $[18,57]$. However, mortality rates were not discussed and experimental settings were slightly different which, in general, makes it difficult to compare results.

As described previously and confirmed in vivo, T2*weighted images revealed engrafted cells scattering discretely throughout the entire lesion area [14-16]. This agrees with the theory that transplanted cells are attracted by, and interact with, tissue regions undergoing degeneration and reorganization [58]. In the acute stage, $48 \mathrm{~h}$ post stroke differences in CSI depended on the injected cell number which we could also sensitively observe by 9.4-T MRI. However, cell signal analysis in the subacute to chronic stage 9 days post MCAo was difficult due to tissue changes initiated by stroke and followed by vasogenic oedema, cell lysis, and the beginning of tissue cavitation, as indicated by the ADC maps [59-61]. Therefore, T2*-weighted signals had to be reanalysed and ASC-derived signals be identified. We could solve this problem by performing a re-analysis of T2\%-weighted images for reliable identification of voxels deriving from ASC signals. After successful voxel analysis we observed no difference in voxel numbers between both MRI examinations in most of the animals that we analysed. Contrary to our findings, Lu et al. observed a clear signal attenuation 14 days post MCAo using 3-T MRI after transplantation of VSOP-labelled MSCs [15]. Since the MRI detection threshold of labelled cells depends on particle concentration per cell, cell density after integration, and MRI parameters such as field strength, 3-T MRI analysis might involve detection limits due to lower contrast-to-noise ratio 
compared to 9.4-T imaging $[62,63]$. As Lu et al. mentioned, this may lead to the assumption of signal loss.

Since we could not observe a signal loss 9 days post MCAo that would have implied cell degradation, we assumed that this result may indicate predominantly vital ASCs, with them being potentially able to proliferate and migrate actively within the brain parenchyma. Subsequent histological analysis using $\mathrm{PB}$ staining as a reliable tool for VSOP-labelled cell visualization revealed PB-positive locations being also positive for VSOP fluorescence and human markers. The fact that almost all the cell cytoplasm of VSOP-labelled ASCs were distinctively blue showed that neither excessive cell degradation nor excessive proliferation activity had taken place because this would have led to weakened staining results in daughter cells as shown in our obtained growth curves. We further tested proliferation activity using Ki67. Positive signals indicated that at least some ASCs had started proliferation. However, our findings do not exclude the possibility of cell degradation taking place or the presence of resting cells at other locations. Despite some challenges due to tissue changes, we consider $\mathrm{T} 2{ }^{*}$-imaging as a very promising tool that might also offer further valuable information about tissue oxygenation in animal and human studies for future applications $[64,65]$.

Because of the observed reduction in infarct size in the group receiving $3 \times 10^{5} \mathrm{ASCs}$, we were interested in migration activity within the brain parenchyma leading to promotion of brain remodelling and neurological recovery [12]. From early observations in the literature we know that stem cells are able to migrate to an ischaemic area very soon after transplantation [66-68]. After analysis of the MRI data of all our groups we found a strong hypointense signal in the right ventricle and striatum of one animal treated with $3 \times 10^{5}$ cells. This signal was confirmed by voxel analysis and was attenuated between $48 \mathrm{~h}$ and 9 days, while a new signal appeared right at the ischaemic border. Histological analysis of this animal revealed residual ASCs in the ventricle and "new" ASCs at the ischaemic border at this location. Although this observation looks very promising, especially due to a decline in infarct volume in the $3 \times 10^{5}$ cell group, the limitation must be noted that this observation could only be made in one animal. The reason for this can probably be found in the fact that locally and temporarily highly limited processes such as cell migration are difficult to capture and that more consecutive MRI examinations and more animals per group may be necessary to solidify our observation.

We are aware of limitations in our study; this applies in particular to the group sizes. As we have already mentioned, the $1 \times 10^{6}$ cell group showed mortality rates twice as high as the other groups. Since mortality rates are rarely discussed in comparable settings, this was surprising for us. The only indications in the literature can be found in a study of Li et al. who observed a mortality rate of $41 \%$ in Wistar rats being injected IA with $1 \times 10^{6}$ NPCs $24 \mathrm{~h}$ after transient $2 \mathrm{~h}$ ischaemia, as well as by Walczak et al. who observed a mortality rate of $67 \%$ in Wistar rats being injected IA with $1 \times 10^{6}$ BMSCs $30 \mathrm{~min}$ after transient $2 \mathrm{~h}$ ischaemia $[14,16]$. Furthermore, we had limited numbers of animals being examined for voxel analysis and residual infarct size post stroke since not every animal underwent both MRI examinations. Nevertheless, the essential statements concerning the effect of different stem cell numbers on engraftment rate and stroke outcome after transient brain ischaemia could be validated with the numbers we had. For upcoming studies we will have to take the limitations, e.g. mortality rate, of this study into account.

Future histological analysis of the animals will pursue interesting issues involving the question of cell location and distribution within the brain after cell delivery and how the initially injected cell number affects the amount and percentage of cells migrating into the brain.

\section{Conclusions}

In conclusion, although IA delivery of SCs is a more invasive method compared to IV injection, it offers the advantage of direct targeting of the damaged tissue. Since cells are solid, they likely have the big disadvantage of provoking impeded CBF and vessel occlusion after injection of high cell numbers. In therapeutic doses, however, systemically delivered SCs may promote brain remodelling and induce functional neurological recovery. Therefore, the future difficulty will be to achieve high cellular engraftment in patients receiving stem cell treatment without the side effects mentioned above. The correct amount of stem cells could be a first step towards the use of an efficient chemoattractive gradient released at the site of the brain lesion.

\section{Additional files}

\footnotetext{
Additional file 1: Supplemental material. (DOCX $18 \mathrm{~kb}$ )

Additional file 2: Figure S1. Influence of VSOP labelling on cell vitality and growth behaviour. LDH release did not differ for unlabelled (negative control) and VSOP-labelled ASCs. Both differed significantly from positive control. ${ }^{*} p<0.05$ for negative control and VSOP-labelled cells vs. positive control (A). Growth curves and fraction of dead cells did not differ between labelled and unlabelled cells at any time (diagram). Growth curves of vital cells increased significantly during the observation period. VSOP density in cytoplasm decreased within 9 days (images). ${ }^{*} p<0.05$ for increased cell growth up to 14 days for VSOP-labelled and unlabelled ASCs (B). ASC adipose tissue-derived stem cell, $L D H$ lactate dehydrogenase, VSOP very small superparamagnetic iron oxide particles. (TIF $6166 \mathrm{~kb}$ )

Additional file 3: Figure S2. Identification and localisation of VSOP-labelled ASCs via PB staining and VSOP fluorescence. Representative images of a PB-stained brain section 14 days post-MCAo of an animal treated with ASCs and enlarged locations within the brain slice. A single ASC is visualized (image 3) and distinguished from the unlabelled rat brain cell. ASCs correlate with locations of VSOP fluorescence
} 
obtained in a neighbour slice (image 8a, blue = DAPI stained cell nuclei, green $=$ VSOPs). ASC adipose tissue-derived stem cell, DAPI 4',6-diamidino-2phenylindole, MCAo middle cerebral artery occlusion, PB Prussian blue, VSOP very small paramagnetic iron oxide particles. (TIF $7415 \mathrm{~kb}$ )

Additional file 4: Figure S3. Identification and viability testing of ASCS via staining of human mitochondria and Ki67. Representative images of PB-positive areas (left images) co-localized with locations positive for human mitochondria (B) and Ki67 (C) (DAB-positive signal, middle images) in neighbour slices whereas negative controls showed no DAB signal (right images). ASC adipose tissue-derived stem cell, DAB 3,3'-diaminobenzidine, PB Prussian blue. (TIF $7971 \mathrm{~kb}$ )

\section{Abbreviations}

ADC: Apparent diffusion coefficient; ASC: Adipose tissue-derived stem cell; BMSC: Bone marrow stromal cell; CBF: Cerebral blood flow; CNS: Central nervous system; CSI: Cell signal intensity; DAB: Diaminobenzidine; DAPI: 4,6-Diamidino-2-phenylindole; DWI: Diffusion-weighted image; ECA: External carotid artery; EDTA: Ethylenediaminetetraacetic acid; FLIRT: FMRIB's Linear Image Registration Tool; FSL: FMRIB's Software Library; IA: Intra-arterially; IQR: Interquartile range; IV: Intravenously; LDH: Lactate dehydrogenase; MCAo: Middle cerebral artery occlusion; MRI: Magnetic resonance imaging; MSC: Mesenchymal stem cell; NPC: Neural progenitor cell; PB: Prussian blue; PBS: Phosphate-buffered saline; ROI: Region of interest; SC: Stem cell; SD: Standard deviation; SS-EPI: Single-shot spinecho echo-planar imaging; TRIS: Tris(hydroxymethyl)aminomethane; VSOP: Very small superparamagnetic iron oxide particles; $\Delta$ CSI: Difference in cell signal intensity

\section{Acknowledgements}

The authors thank Mrs. Andrea Braun-Kornmüller and Mrs. Anna Roedl for technical support.

\section{Funding}

Not applicable.

\section{Availability of data and materials}

All dataset(s) supporting the conclusions of this article are included within the article.

\section{Authors' contributions}

SG has the main responsibility for article conception and design (including graphic presentations and MRI image selection for presentation) as well as data acquisition which mainly includes measurements of infarct sizes and $\Delta C S$ I. Furthermore she is the main responsible person for data analysis and interpretation which includes MRI-derived data ( $\triangle \mathrm{CSI}$, infarct sizes, and voxel analysis) as well as comparison between histological and MRI-derived data. Furthermore, she is the main responsible person for the draft of the article and revision, as well as final approval of the version to be published. SB contributed substantially to MRI sequence optimization and measurements as well as acquisition and analysis of $\Delta \mathrm{CSI}$. He also contributed to critical article revision for intellectual content and is also responsible for final approval of the version to be published. AE contributed substantially to statistical data analysis and interpretation. She also contributed to critical article revision for intellectual content and is also responsible for final approval of the version to be published. PP contributed substantially to re-analysis of the MRI data for acquisition of hypointense voxels. He also contributed to critical article revision for intellectual content and is also responsible for final approval of the version to be published. AL contributed substantially to MRI sequence establishment as well as MRI measurements. He also contributed to critical article revision for intellectual content and is also responsible for final approval of the version to be published. KB contributed to data interpretation. She also contributed substantially to critical article revision for intellectual content and is also responsible for final approval of the version to be published. RMD contributed to re-analysis of MRI data for acquisition of hypointense voxels. He also contributed substantially to critical article revision for intellectual content and is also responsible for final approval of the version to be published. LRS contributed to MRI sequence establishment. He also contributed substantially to critical article revision for intellectual content and is also responsible for final approval of the version to be published. AA contributed to data interpretation. She also contributed substantially to critical article revision for intellectual content and is also responsible for final approval of the version to be published.
MGH contributed to data interpretation. He also contributed substantially to critical article revision for intellectual content and is also responsible for final approval of the version to be published. MF contributed substantially to article conception as well as interpretation of data. He also contributed substantially to critical article revision for intellectual content and is also responsible for final approval of the version to be published. Every author has given final approval of the version to be published and has sufficiently participated in the work to take public responsibility for appropriate portions of the content. In addition, every author has agreed to be accountable for all aspects of the work in ensuring that questions related to the accuracy or integrity of any part of the work are appropriately investigated and resolved.

\section{Authors' information}

Not applicable.

\section{Competing interests \\ The authors declare that they have no competing interests.}

\section{Consent for publication}

Not applicable.

\section{Ethics approval and consent to participate}

Human ASCs were obtained from one donor undergoing liposuction. Written informed consent was obtained from the donor including consent to participate in the study. Experimental research was performed in compliance with the Helsinki Declaration. The isolation and use of human ASCs was approved by the responsible ethics committee (2009-210 N-MA and 2006-192 N-MA; Medical Faculty, Mannheim). All animal procedures were approved by the responsible ethics committee according to $\S 15$ Tierschutzgesetz, located in the Regierungspräsidium (regional council) Karlsruhe, Department 3, agriculture, area for agricultural use, veterinary and food, 76247 Karlsruhe, state of Baden-Württemberg, Germany. The ethics committee has the same number as the approved study (35-9185.81/G-59/ 09). The study was approved according to section 8(1) of the German animal protection law dated 7 June 2006 (BGBI. I S 1313) and given the reference number 35-9185.81/G-59/09 according to the number of the ethics committee. A translated version of the approval mentioning the ethics committee/reference number is provided in the supplements. Additionally al procedures were performed in strict accordance with European guidelines and German law for the care and use of laboratory animals (amendment in effect July 2013).

\section{Publisher's Note}

Springer Nature remains neutral with regard to jurisdictional claims in published maps and institutional affiliations.

\section{Author details \\ ${ }^{1}$ Department of Neurology, Universitätsmedizin Mannheim, Heidelberg University, Theodor-Kutzer-Ufer 1-3, D-68167 Mannheim, Germany. ${ }^{2}$ Computer Assisted Clinical Medicine, Medical Faculty Mannheim, Heidelberg University, 68167 Mannheim, Germany. ${ }^{3}$ Department of Radiology, UZ-Brussel, Vrije Universiteit (VUB), 1090 Brussels, Belgium. ${ }^{4}$ Institute of Transfusion Medicine and Immunology, Medical Faculty Mannheim, Heidelberg University, 68167 Mannheim, Germany. ${ }^{5}$ Biomedical MR Imaging and Spectroscopy Group, Image Sciences Institute, University Medical Center} Utrecht, 3584 CX Utrecht, The Netherlands.

Received: 24 January 2017 Accepted: 25 March 2017 Published online: 26 April 2017

\section{References}

1. Bourin P, Bunnell BA, Casteilla L, Dominici M, Katz AJ, March KL, Redl H, Rubin JP, Yoshimura K, Gimble JM. Stromal cells from the adipose tissuederived stromal vascular fraction and culture expanded adipose tissuederived stromal/stem cells: a joint statement of the International Federation for Adipose Therapeutics and Science (IFATS) and the International Society for Cellular Therapy (ISCT). Cytotherapy. 2013;15:641-8.

2. Bunnell BA, Flaat M, Gagliardi C, Patel B, Ripoll C. Adipose-derived stem cells: isolation, expansion and differentiation. Methods. 2008;45:115-20. 
3. De Francesco F, Ricci G, D'Andrea F, Nicoletti GF, Ferraro GA. Human adipose stem cells: from bench to bedside. Tissue Eng Part B Rev. 2015;21:572-84.

4. Salehi H, Amirpour N, Niapour A, Razavi S. An overview of neural differentiation potential of human adipose derived stem cells. Stem Cell Rev. 2016;12(1):26-41.

5. Lindroos $B$, Suuronen $R$, Miettinen $S$. The potential of adipose stem cells in regenerative medicine. Stem Cell Rev. 2011;7:269-91.

6. Yoo KH, Jang IK, Lee MW, Kim HE, Yang MS, Eom Y, Lee JE, Kim YJ, Yang SK, Jung $\mathrm{HL}$, et al. Comparison of immunomodulatory properties of mesenchymal stem cells derived from adult human tissues. Cell Immunol. 2009;259:150-6.

7. Melief SM, Zwaginga JJ, Fibbe WE, Roelofs H. Adipose tissue-derived multipotent stromal cells have a higher immunomodulatory capacity than their bone marrow-derived counterparts. Stem Cells Transl Med. 2013;2:455-63.

8. McIntosh KR, Lopez MJ, Borneman JN, Spencer ND, Anderson PA, Gimble JM. Immunogenicity of allogeneic adipose-derived stem cells in a rat spinal fusion model. Tissue Eng Part A. 2009;15:2677-86.

9. Salgado AJ, Reis RL, Sousa NJ, Gimble JM. Adipose tissue derived stem cells secretome: soluble factors and their roles in regenerative medicine. Curr Stem Cell Res Ther. 2010;5:103-10.

10. Cawthorn WP, Scheller EL, MacDougald OA. Adipose tissue stem cells: the great WAT hope. Trends Endocrinol Metab. 2012;23:270-7.

11. Kilroy GE, Foster SJ, Wu X, Ruiz J, Sherwood S, Heifetz A, Ludlow JW, Stricker DM, Potiny $S$, Green $P$, et al. Cytokine profile of human adipose-derived stem cells: expression of angiogenic, hematopoietic, and pro-inflammatory factors. J Cell Physiol. 2007;212:702-9.

12. Hermann DM, Peruzzotti-Jametti L, Schlechter J, Bernstock JD, Doeppner TR, Pluchino S. Neural precursor cells in the ischemic brain-integration, cellular crosstalk, and consequences for stroke recovery. Front Cell Neurosci. 2014;8:291.

13. Kraitchman DL, Tatsumi M, Gilson WD, Ishimori T, Kedziorek D, Walczak P, Segars WP, Chen HH, Fritzges D, Izbudak I, et al. Dynamic imaging of allogeneic mesenchymal stem cells trafficking to myocardial infarction. Circulation. 2005;112:1451-61.

14. Li L, Jiang Q, Ding G, Zhang L, Zhang ZG, Li Q, Panda S, Lu M, Ewing JR, Chopp M. Effects of administration route on migration and distribution of neural progenitor cells transplanted into rats with focal cerebral ischemia, an MRI study. J Cereb Blood Flow Metab. 2010;30:653-62.

15. Lu SS, Liu S, Zu QQ, Xu XQ, Yu J, Wang JW, Zhang Y, Shi HB. In vivo MR imaging of intraarterially delivered magnetically labeled mesenchymal stem cells in a canine stroke model. PLoS One. 2013;8:e54963.

16. Walczak P, Zhang J, Gilad AA, Kedziorek DA, Ruiz-Cabello J, Young RG, Pittenger MF, van Zijl PC, Huang J, Bulte JW. Dual-modality monitoring of targeted intraarterial delivery of mesenchymal stem cells after transient ischemia. Stroke. 2008;39:1569-74.

17. Ishizaka S, Horie N, Satoh K, Fukuda Y, Nishida N, Nagata I. Intra-arterial cell transplantation provides timing-dependent cell distribution and functional recovery after stroke. Stroke. 2013;44:720-6.

18. Keimpema E, Fokkens MR, Nagy Z, Agoston V, Luiten PG, Nyakas C, Boddeke HW, Copray JC. Early transient presence of implanted bone marrow stem cells reduces lesion size after cerebral ischaemia in adult rats. Neuropathol Appl Neurobiol. 2009;35:89-102.

19. Bieback K, Schallmoser K, Kluter $H$, Strunk D. Clinical protocols for the isolation and expansion of mesenchymal stromal cells. Transfus Med Hemother. 2008;35:286-94.

20. Giesel FL, Stroick M, Griebe M, Troster H, von der Lieth CW, Requardt M, Rius M, Essig M, Kauczor HU, Hennerici MG, Fatar M. Gadofluorine M uptake in stem cells as a new magnetic resonance imaging tracking method-an in vitro and in vivo study. Investig Radiol. 2006;41:868-73.

21. Stroh A, Zimmer C, Gutzeit C, Jakstadt M, Marschinke F, Jung T, Pilgrimm $H$, Grune T. Iron oxide particles for molecular magnetic resonance imaging cause transient oxidative stress in rat macrophages. Free Radic Biol Med. 2004;36:976-84.

22. Kilkenny C, Browne W, Cuthill IC, Emerson M, Altman DG. National Centre for the Replacement, Refinement, and Reduction of Animals in Research. Animal research: reporting in vivo experiments-the ARRIVE guidelines. J Cereb Blood Flow Metab. 2011;31:991-3.

23. Koizumi JYY, Nakazawa T, Ooneda G. Experimental studies of ischemic brain edema. 1. A new experimental model of cerebral embolism in rats in which recirculation can be introduced in the ischemic area. Jpn J Stroke. 1986;8:1-8.
24. Longa EZ, Weinstein PR, Carlson S, Cummins R. Reversible middle cerebral artery occlusion without craniectomy in rats. Stroke. 1989;20:84-91.

25. Himmelreich $U$, Hoehn M. Stem cell labeling for magnetic resonance imaging. Minim Invasive Ther Allied Technol. 2008;17:132-42.

26. Tustison N, Gee J. N4ITK: Nick's N3 ITK implementation for MRI BIAS field correction. Inside J. 2009:1-8.

27. Smith SM, Jenkinson M, Woolrich MW, Beckmann CF, Behrens TE, JohansenBerg $\mathrm{H}$, Bannister PR, De Luca M, Drobnjak I, Flitney DE, et al. Advances in functional and structural MR image analysis and implementation as FSL. Neuroimage. 2004;23 Suppl 1:S208-219.

28. Trekker J, Leten C, Struys T, Lazenka W, Argibay B, Micholt L, Lambrichts I, Van Roy W, Lagae L, Himmelreich U. Sensitive in vivo cell detection using size-optimized superparamagnetic nanoparticles. Biomaterials. 2014;35:1627-35.

29. Argibay B, Trekker J, Himmelreich U, Beiras A, Topete A, Taboada P, PerezMato M, Sobrino T, Rivas J, Campos F, Castillo J. Easy and efficient cell tagging with block copolymers based contrast agents for sensitive MRI detection in vivo. Cell Transplant. 2016;25(10):1787-800.

30. Rosenblum S, Wang N, Smith TN, Pendharkar AV, Chua JY, Birk H, Guzman R. Timing of intra-arterial neural stem cell transplantation after hypoxiaischemia influences cell engraftment, survival, and differentiation. Stroke. 2012;43:1624-31.

31. Rossetti T, Nicholls F, Modo M. Intracerebral cell implantation: preparation and characterization of cell suspensions. Cell Transplant. 2016;25:645-64.

32. Kondziolka D, Gobbel GT, Fellows-Mayle W, Chang YF, Uram M. Injection parameters affect cell viability and implant volumes in automated cell delivery for the brain. Cell Transplant. 2011;20:1901-6.

33. Amer MH, Rose FR, White LJ, Shakesheff KM. A detailed assessment of varying ejection rate on delivery efficiency of mesenchymal stem cells using narrow-bore needles. Stem Cells Transl Med. 2016:5:366-78.

34. Darsalia V, Allison SJ, Cusulin C, Monni E, Kuzdas D, Kallur T, Lindvall O, Kokaia Z. Cell number and timing of transplantation determine survival of human neural stem cell grafts in stroke-damaged rat brain. J Cereb Blood Flow Metab. 2011;31:235-42.

35. Griffin MD, Ryan AE, Alagesan S, Lohan P, Treacy O, Ritter T. Anti-donor immune responses elicited by allogeneic mesenchymal stem cells: what have we learned so far? Immunol Cell Biol. 2013;91:40-51.

36. Hovakimyan M, Muller J, Wree A, Ortinau S, Rolfs A, Schmitt O. Survival of transplanted human neural stem cell line (ReNcell VM) into the rat brain with and without immunosuppression. Ann Anat. 2012;194:429-35.

37. Fatar M, Stroick M, Griebe M, Marwedel I, Kern S, Bieback K, Giesel FL, Zechmann C, Kreisel S, Vollmar F, et al. Lipoaspirate-derived adult mesenchymal stem cells improve functional outcome during intracerebra hemorrhage by proliferation of endogenous progenitor cells stem cells in intracerebral hemorrhages. Neurosci Lett. 2008:443:174-8.

38. Bjorklund A, Lindvall O. Cell replacement therapies for central nervous system disorders. Nat Neurosci. 2000;3:537-44.

39. Guzman R, Bliss T, De Los AA, Moseley M, Palmer T, Steinberg G. Neural progenitor cells transplanted into the uninjured brain undergo targeted migration after stroke onset. J Neurosci Res. 2008;86:873-82.

40. Yilmaz G, Vital S, Yilmaz CE, Stokes KY, Alexander JS, Granger DN. Selectinmediated recruitment of bone marrow stromal cells in the postischemic cerebral microvasculature. Stroke. 2011;42:806-11.

41. Fischer UM, Harting MT, Jimenez F, Monzon-Posadas WO, Xue H, Savitz SI, Laine GA, Cox Jr CS. Pulmonary passage is a major obstacle for intravenous stem cell delivery: the pulmonary first-pass effect. Stem Cells Dev. 2009;18:683-92.

42. Lee RH, Pulin AA, Seo MJ, Kota DJ, Ylostalo J, Larson BL, Semprun-Prieto L, Delafontaine P, Prockop DJ. Intravenous hMSCs improve myocardial infarction in mice because cells embolized in lung are activated to secrete the anti-inflammatory protein TSG-6. Cell Stem Cell. 2009;5:54-63.

43. Gholamrezanezhad A, Mirpour S, Bagheri M, Mohamadnejad M, Alimoghaddam K, Abdolahzadeh L, Saghari M, Malekzadeh R. In vivo tracking of 111 In-oxine labeled mesenchymal stem cells following infusion in patients with advanced cirrhosis. Nucl Med Biol. 2011;38:961-7.

44. Eggenhofer E, Benseler V, Kroemer A, Popp FC, Geissler EK, Schlitt HJ, Baan CC, Dahlke MH, Hoogduijn MJ. Mesenchymal stem cells are short-lived and do not migrate beyond the lungs after intravenous infusion. Front Immunol. 2012;3:297.

45. Barbash IM, Chouraqui $P$, Baron J, Feinberg MS, Etzion S, Tessone A, Miller L Guetta E, Zipori D, Kedes LH, et al. Systemic delivery of bone marrow- 
derived mesenchymal stem cells to the infarcted myocardium: feasibility, cell migration, and body distribution. Circulation. 2003;108:863-8.

46. Furlani D, Ugurlucan M, Ong L, Bieback K, Pittermann E, Westien I, Wang W, Yerebakan C, Li W, Gaebel R, et al. Is the intravascular administration of mesenchymal stem cells safe? Mesenchymal stem cells and intravital microscopy. Microvasc Res. 2009;77:370-6.

47. Makela T, Takalo R, Arvola O, Haapanen H, Yannopoulos F, Blanco R, Ahvenjarvi L, Kiviluoma K, Kerkela E, Nystedt J, et al. Safety and biodistribution study of bone marrow-derived mesenchymal stromal cells and mononuclear cells and the impact of the administration route in an intact porcine model. Cytotherapy. 2015;17:392-402.

48. Moll G, Rasmusson-Duprez I, von Bahr L, Connolly-Andersen AM, Elgue G, Funke L, Hamad OA, Lonnies H, Magnusson PU, Sanchez J, et al. Are therapeutic human mesenchymal stromal cells compatible with human blood? Stem Cells. 2012;30:1565-74

49. Tatsumi K, Ohashi K, Matsubara Y, Kohori A, Ohno T, Kakidachi H, Horii A, Kanegae K, Utoh R, Iwata T, Okano T. Tissue factor triggers procoagulation in transplanted mesenchymal stem cells leading to thromboembolism. Biochem Biophys Res Commun. 2013:431:203-9.

50. Gleeson BM, Martin K, Ali MT, Kumar AHS, Pillai MGK, Kumar SPG, O'Sullivan JF, Whelan D, Stocca A, Khider W, et al. Bone marrow-derived mesenchymal stem cells have innate procoagulant activity and cause microvascular obstruction following intracoronary delivery: amelioration by antithrombin therapy. Stem Cells. 2015;33:2726-37.

51. Moll G, Ignatowicz L, Catar R, Luecht C, Sadeghi B, Hamad O, Jungebluth P, Dragun D, Schmidtchen A, Ringden O. Different procoagulant activity of therapeutic mesenchymal stromal cells derived from bone marrow and placental decidua. Stem Cells Dev. 2015;24:2269-79.

52. Le Blanc K, Rasmusson I, Sundberg B, Gotherstrom C, Hassan M, Uzunel M, Ringden $\mathrm{O}$. Treatment of severe acute graft-versus-host disease with third party haploidentical mesenchymal stem cells. Lancet. 2004;363:1439-41.

53. Meisel C, Schwab JM, Prass K, Meisel A, Dirnagl U. Central nervous system injury-induced immune deficiency syndrome. Nat Rev Neurosci. 2005;6:775-86.

54. Le Blanc K, Frassoni F, Ball L, Locatelli F, Roelofs H, Lewis I, Lanino E, Sundberg B, Bernardo ME, Remberger M, et al. Mesenchymal stem cells for treatment of steroid-resistant, severe, acute graft-versus-host disease: a phase II study. Lancet. 2008;371:1579-86.

55. Miura Y, Kami M, Tsubokura M, Takei N, Komatsu T. Mesenchymal stem cells for acute graft-versus-host disease. Lancet. 2008:372:715-6. author reply 716.

56. Stephenne X, Nicastro E, Eeckhoudt S, Hermans C, Nyabi O, Lombard C, Najimi M, Sokal E. Bivalirudin in combination with heparin to control mesenchymal cell procoagulant activity. PLoS One. 2012;7:e42819.

57. Kamiya N, Ueda M, Igarashi H, Nishiyama Y, Suda S, Inaba T, Katayama Y. Intra-arterial transplantation of bone marrow mononuclear cells immediately after reperfusion decreases brain injury after focal ischemia in rats. Life Sci. 2008:83:433-7.

58. Modo M, Stroemer RP, Tang E, Patel S, Hodges H. Effects of implantation site of stem cell grafts on behavioral recovery from stroke damage. Stroke. 2002;33:2270-8.

59. Allen LM, Hasso AN, Handwerker J, Farid H. Sequence-specific MR imaging findings that are useful in dating ischemic stroke. Radiographics. 2012;32:1285-97.

60. Matsumoto K, Lo EH, Pierce AR, Wei H, Garrido L, Kowall NW. Role of vasogenic edema and tissue cavitation in ischemic evolution on diffusionweighted imaging: comparison with multiparameter MR and immunohistochemistry. AJNR Am J Neuroradiol. 1995;16:1107-15.

61. Srinivasan A, Goyal M, Al Azri F, Lum C. State-of-the-art imaging of acute stroke. Radiographics. 2006;26 Suppl 1:S75-95.

62. Heyn C, Ronald JA, Mackenzie LT, MacDonald IC, Chambers AF, Rutt BK, Foster PJ. In vivo magnetic resonance imaging of single cells in mouse brain with optical validation. Magn Reson Med. 2006;55:23-9.

63. Magnitsky S, Watson DJ, Walton RM, Pickup S, Bulte JW, Wolfe JH, Poptani $\mathrm{H}$. In vivo and ex vivo MRI detection of localized and disseminated neural stem cell grafts in the mouse brain. Neuroimage. 2005;26:744-54.

64. Domsch S, Mie MB, Wenz F, Schad LR. Non-invasive multiparametric qBOLD approach for robust mapping of the oxygen extraction fraction. Z Med Phys. 2014;24:231-42.

65. Sedlacik J, Reitz M, Bolar DS, Adalsteinsson E, Schmidt NO, Fiehler J. Correlation of oxygenation and perfusion sensitive MRI with invasive micro probe measurements in healthy mice brain. Z Med Phys. 2015;25:77-85.
66. Hoehn M, Kustermann E, Blunk J, Wiedermann D, Trapp T, Wecker S, Focking M, Arnold H, Hescheler J, Fleischmann BK, et al. Monitoring of implanted stem cell migration in vivo: a highly resolved in vivo magnetic resonance imaging investigation of experimental stroke in rat. Proc Natl Acad Sci U S A. 2002;99:16267-72.

67. Modo M, Mellodew K, Cash D, Fraser SE, Meade TJ, Price J, Williams SC. Mapping transplanted stem cell migration after a stroke: a serial, in vivo magnetic resonance imaging study. Neuroimage. 2004;21:311-7.

68. Zhang ZG, Jiang Q, Zhang R, Zhang L, Wang L, Zhang L, Arniego P, Ho KL, Chopp M. Magnetic resonance imaging and neurosphere therapy of stroke in rat. Ann Neurol. 2003;53:259-63.

\section{Submit your next manuscript to BioMed Central and we will help you at every step:}

- We accept pre-submission inquiries

- Our selector tool helps you to find the most relevant journal

- We provide round the clock customer support

- Convenient online submission

- Thorough peer review

- Inclusion in PubMed and all major indexing services

- Maximum visibility for your research

Submit your manuscript at www.biomedcentral.com/submit
Biomed Central 